\title{
COLLECTING SOUNDS. ONLINE SHARING OF FIELD RECORDINGS AS CULTURAL PRACTICE
}

\author{
AGATA STANISZ \\ DEPARTMENT OF ANTHROPOLOGY AND ETHNOLOGY, \\ ADAM MICKIEWICZ UNIVERSITY, POZNAŃ
}

\begin{abstract}
Field recording is a sound practice that gains increasingly more popularity nowadays. We can observe effects of this practice in two contexts: I. On the websites dedicated to digital sound production; 2. During the activities accompanying various artistic, cultural and educational events. I consider the first context in which I participate as a fieldrecordist, who uses sound recording as a non-visual method of (audio) anthropology. The goal of this article is to look into the field recording as a category of socio-cultural practice related to the technological development and growing significance of sound production, and more generally, to the global process of sounding the western, mainly urban, culture.

Websites dedicated to audio recordings are used to publish and share sounds collected by tourists and other travellers, who catch sounds in the same way as they take photographs. These recordings are brought from exotic vacations, business trips, sightseeing tours, or sentimental journeys. Analysis of field recording practices encourages a broader reflection on the status of sounds, why some of them are audible and others are not, how new technologies influence the processes of democratisation of senses and raise public awareness of the importance of acoustic space. Moreover, tourist field recording enable us to take a closer look at the stereotypical hearing and listening processes, as well as the cultural mechanisms of exoticising non-European/non-urban soundscapes.
\end{abstract}

K E Y W O R D S : field recording, audioanthropology, sound technology, digital anthropology, cultural pratice

A French composer from suburban Paris creating music for a theatre, who commutes to work by train every day; an American drummer traveling around the islands of Indonesia; an ethnology student fascinated with industrial music, who lives in the suburbs of Barcelona; an admirer of hiking in the wild places of the US; an Australian, the founder of Trans Industrial Toy Orchestra, who lives with his grandparents in Oldenburg; an Italian musician from Parma on vacation in Zadar; a Dutch manager in medialab in Amsterdam, living in Rotterdam, involved in sound projects in Switzerland, who went on holiday to the Canary Islands; a font designer from Brazil who occasionally records ambiences of Santos for a company from Israel; a Finnish internist who travels more than $600 \mathrm{~km}$ to enjoy his inherited cottage in the countryside; an 
American graphic designer and amateur anthropologist from Boise in Idaho, who loves listening to people's stories; a Hawaiian admirer of electromechanical sirens; an American tourist who got lost on a housing estate in Rio de Janeiro; a Dutch professor of the history of electronic music strolling through a church garden in the centre of Florence; an English radio journalist from York; an IT specialist from Greenville, who works at home; a sound artist from Berlin, who teaches in Seoul; a European citizen currently living in Belgium, realizing sound and musical projects in Asia; a Dutch journalist doing a story on the tsunami devastation in Bangladesh; a Polish sound technician providing sound systems for various events throughout the whole country; a German biology teacher on a trip with his students; a Canadian soccer fan temporarily living in Genoa; an English Jew on a trip to Israel; a Hollywood resident involved in citizen journalism; a documentary filmmaker from Denmark dealing with a movie project in Delhi; an English tourist in Africa for the first time; an Australian who got married in Cuba.

What connects these people? Each of them is a collector of sounds. They are field recordists - more or less professionals - gathered around an Internet collaborative repository of sounds that gives the possibility to reuse the sounds released under Creative Commons licenses ${ }^{\mathrm{I}}$. In other words, they are representatives of an online community of people who make, share, distribute and remix field recordings; a community which believes in the idea of free culture (Lessig 2004; Fitzgerald 2007) that promotes the freedom to distribute and modify creative works in the form of free or open content by using the Internet and other forms of media ${ }^{2}$. From the anthropological point of view, such a movement emerging around field recording can be considered as an example of a cultural practice (Choe and Ko 20I5).

I Creative Commons is an American non-profit organization devoted to expanding the range of creative works available for others to build upon legally and to share. The organization has released several copyright licenses, known as Creative Commons licenses, free of charge to the public. These licenses allow creators to communicate which rights they reserve and which rights they waive for the benefit of recipients or other creators. They replace the individual negotiations for specific rights between copyright owner (licensor) and licensee, which are necessary under „all rights reserved” copyright management, with „some rights reserved” management employing standardized licenses for re-use, wherein no commercial compensation is sought by the copyright owner. The first set of copyright licenses was released in December 2002. See: https://creativecommons.org/ (accessed I0.07.2017).

2 The free culture movement has objections towards over-restrictive copyright laws. It argues that such laws hinder creativity and calls for a permission culture system. The movement, with its ethos of free exchange of ideas, is aligned with the free and open source software movement. Today, the term stands for many other movements, including open access (OA) culture, remix culture, hacker culture, the access to knowledge movement, Open Source Learning, the copyleft movement and the public domain movement. 
Field recording is a sound practice that nowadays is gaining more popularity. I am myself a field recordist who uses sound recording as a non-visual method of (audio) anthropology (Stanisz 20I2a; 20I2b, 99-III; 20I4, 305-318; 20I7, I-I9), but one who also looks into field recording as a category of socio-cultural practices related to the technological development and growing significance of sound production, or more generally, to the global process of sounding western culture. There are hundreds of websites dedicated to audio recordings (audio snippets, samples, bleeps, sound effects, field recordings) that make it possible to publish, share and reuse sounds that are very often collected by tourists and other travellers who catch sounds in the same way as they take photographs (see Cusack 20I2) ${ }^{3}$. These recordings are gathered from different places: as part of exotic tours, business trips, sightseeing or just sentimental journeys. The example of field recording practices encourages a broader reflection on the status of sounds: why some of them are audible and others are not; and how new technologies influence the process of the democratization of the senses and raise public awareness of the importance of acoustic space. Moreover, the phenomenon of tourist field recording makes it possible to take a closer look at stereotypical hearing and listening, as well as at the cultural mechanisms of exoticizing non-European or non-urban soundscapes.

Practising field recording is not pure and free of, often unconscious, processes essentializing a given cultural context (see Wyness 2008). Field recording is sometimes an ideologized and discursive activity. In social and humanities' studies, it is related to the concept of soundscape, which refers not only to urban, rural, public, household, natural and mechanical sounds (Schafer 1977), but also to sounds composed, created and recorded by people, such as musicians, artists, journalists, archivists, phonographers, folklorists, sociologists and anthropologists, with the help of various technologies (Truax 1996, 49-65; 2008, 103-109; 2012, I-9). As a sonic type of landscape, a soundscape doubtlessly undergoes processes of aesthetic or symbolic valuation and branding. Thus, its production, registration, manipulation and the creation of the forms in which it is represented belong to different discursive practices, which can be social, institutional, religious, scientific and artistic. The interest in experiencing the world acoustically has grown since more and more sounds started being produced due to industrialization, and has intensified in tandem with the emergence of IT processes, the development of multi-channel communication and the digitization of basically everything in complex societies (Choe and Ko 2015; Lin 2015, 187-197).

On the one hand, the unlimited possibilities to reproduce, archive, manipulate and distribute sounds offered by technology and the media have caused the traditional

3 One of the most popular tools for disseminating field recordings are sound maps. See the Internet platform "Sound Cartography", which offers a review of over 70 global sound maps: https://soundcartography.wordpress.com/ (accessed on 02.08.2018). 
boundaries between sound and music to disintegrate. This blurring of boundaries has led to new acoustic practices coming to life that create new cultural and auditive knowledge and identity systems. On the other hand, we can observe a phenomenon of the acoustic aestheticization of life (daily activities, consumption, knowledge) and of sound itself, which can be exemplified by field recordings that enclose a fragmented reality in sound postcards, samples, soundtracks or subjective mental maps. What this brings about is an intensive discursification of sound awareness and acoustic experience, which hyperbolizes the sense of hearing and contrasts it with visuality.

Something is happening with sound, and not only in terms of scientific, academic or artistic communities. The process of increasingly appreciating sound and a more pronounced acoustic awareness has to be connected to the development of technologies enabling people to register sounds. It was at the end of the $19^{\text {th }}$ century when the phonograph was invented, and from the outset this technology was used by researchers to study musical and spoken folklore. However, in my opinion, field recording in its non-scientific, non-academic version appeared only when the possibility to share, i.e. to distribute and remix one's field recordings was developed on a large scale. The field recording boom is, therefore, not so much a matter of the appearance of increasingly sophisticated, easy-to-use, portable recording equipment (recorders and microphones), as it is a product of the development of Internet websites, such as Web 2.0 created after 200I, which are solely based on the content generated by Internet users (O'Reilly 2005; Lin 2015, 187-197).

Thus, the history of field recording and its modes of use is a history of the appearance and development of sound registering technologies, and only in this context can it be accurately described (Caughie 2010, 9I-IO9). It is complicated to analyze the history of using field recording as a scientific method of creating audio data, because from the very beginning it was simultaneously applied in different scientific disciplines, as well in as various music and music-related artistic trends.

The idea of field recording involves making sound recordings (whether they are analogue, digital, musical or non-musical) in the so-called field, far away from the recording studio, in conditions that are somewhat unpredictable. However, perceiving field recording as the mere registration of sounds from the world around us does not exhaust the contemporary understanding of this notion. For this term also covers the art of the manipulation of field recordings, e.g. their editing and contextual use, which deprives them of their purity and objectivity. Field recordings should always be perceived as involved in the context both of their creation and of their distribution. Both the practice of registering sounds and the impacts of the sounds thus made available are conditioned by history, culture, society, politics and the environment. Recording is thus an activity whose inherent components are verification, analysis and interpretation, and whose history is not only the history of evolution of recording equipment and the techniques of using it, but also that of the history of listening and hearing (Sterne 2003). 
Generally, field recordings can be divided into two categories: natural sounds (e.g. animal or ocean sounds, forest whispers, wind blowing) and sounds generated by people (e.g. street traffic, public places, construction machines, all types of vocal and bodily sounds). They are described as phonographic, a term which indicates their analogy to the socio-cultural function and role of photography. This type of recording outside the studio initially appeared as additional documentation created during field work (ethnographic, musicological, linguistic or geographic) and during the production of sound effects in cinematography. At the beginning, the recordings of natural sounds were used mainly in documentaries, and only later did they gain not only commercial, but also symbolic and scientific significance. Among the main factors contributing to changing the way non-music sounds were perceived should certainly be counted the activity of the famous composer of silence John Cage and the work of Alvin Lucier, who in the I960s was already creating sound installations.

Technological development, especially in terms of improving sound quality, brought about more and more compact recorders. As a result, field recordings became a separate genre: something in between alternative music, avant-garde, experimental, ambient or musique concrète. Recordings were used more and more intensively by scientists and researchers. Field recording understood as the registration of atmosphere types (ambiences) which are supposed to reflect the acoustic character of a given place, its special quality and dynamics, has developed since the end of the $19^{\text {th }}$ century. However, it gained popularity as late as in the I970s through a series of soundscapes with birds singing, rain falling, waves crashing or leaves rustling on trees, called "Environments", created by Irv Teibel from 1969 to 1979. These published recordings were an immediate hit on the market, making Teibel the person who introduced the sounds of nature to the public (Ballard 2018).

Field recordings also comprise monaural or stereophonic recordings of vocal and music folklore registered in various folk-creating contexts, the history of which goes back to the 1930s. Field recording in this sense is mainly made and presented within the domain of ethnomusicology, where from the very beginning it was used as a way of documenting musical and extramusical voice performances. Pioneers in this area were Charles Seeger and John Lomax (Porterfield 1996; Yung and Rees 1999). Moreover, the role of field recordings and field recording activities in arts should not be overlooked, especially when it comes to the development of ambient music or musique concrète, whose main pioneer, both in terms of theory and practice, was Pierre Schaeffer. In this discussion, we also should not leave out Raymond Murray Schaferthe author of the influential transdisciplinary concept of soundscape. Since his pioneering work in the 1960s (Schafer 1977), soundscape research has evolved into a multidisciplinary field (Raimbault and Dubois 2005, 339-350). The methods and ideas developed in Schafer's multidisciplinary approach to the relations between sounds and society have inspired a variety of fields, including cultural history of sounds, 
qualitative research on the sonic environment and acoustic communication (Uimonen and Kytö 2008, I5-2I). Soundscape research seeks to understand how sounds, both from natural and human-made sources, "can be used to understand the coupled nature-human dynamics across different spatial and temporal scales" (Pijanowski et al. 2OII, I2I3-I232). In particular, recording and listening to various sounds is an important area of soundscape research (Kang 2006). One of the major goals of researching these practices is to engage in the notion of "care for the sonic environment" through "listening with care" (Westerkamp 1974, I8-27; 2000, 7-13), which may constitute "a tending to the soul that resides in nature as well as in human beings" (Moore 1992, 270). As such, this body of work draws upon acoustic ecology and seeks to improve the quality of a soundscape. While this is an important area in soundscape research, I consider the strand of work that examines the social and cultural environment shaping our perceptions of sounds (Kang 2006) more relevant to my study in this article. In particular, I draw upon three perspectives from this area of my work. The first is that of the efforts made to map soundscapes; the second is the discussions around and practices of listening to landscapes, usually in an artistic context; and the third is that of examining the production of soundscapes as a social and cultural practice. These three fields are related, pointing to the importance of examining the fluidity and hybridity of soundscapes, and their relations with the environment and society (Lin 2015, 187-197).

More or less at the beginning of the $2 \mathrm{I}^{\mathrm{st}}$ century, field recording took on a more social aspect and became one of the most important audio phenomena on various mushrooming websites gathering people active in the music industry. These websites provide the opportunity to share sounds: from single, autonomous and invoked sounds to (more often) elements of whole soundscapes. In 2006, I became interested in the communities which were formed around those websites, and I started my first attempts at registering sounds in the field. As a result, I have been doing field recording for I2 years, since conducting elective classes at the AMU Institute of Ethnology and Cultural Anthropology in Poznań called "City Project: Space, Activities, Presence." These were aimed at creating alternative maps of Poznan city centre. On the basis of the knowledge that I had gathered till then and a small, far from perfect, collection of sound recordings, I created "Soundmap - an alternative map of Poznańt". This miniproject consisted of a situational floating through the streets of Poznan and listening

4 In 2009, on the basis of the gathered recordings, a miniature sound map of Poznan was created as a part of a more comprehensive Internet project PalimpsestMaps. The project was carried out as a part Urban Legend Art in the Public Space Festival organized by Academy of Fine Arts in Poznań (today the University of Arts). It was available on the Internet until May 2018. Its homepage was archived in March 2018 in the Internet Archive, Wayback Machine: https://web.archive.org/ (accessed on 09.08.2018). 
attentively to the sounds they were generating. Initially, this task was not easy, as it was accompanied by a feeling of walking aimlessly and recording ordinary and typical sounds of everyday life. This is why my first recordings were of music in public spaces: a street busker and a brass band. This shows that the sounds I found interesting were not from normal daily life, but rather were somewhat exotic in the acoustic environments of the city. However, it soon turned out that the general ambience was mainly about the everyday buzz, drones and screeches of the streets. This small sound collection led me in 2009 to a community gathered around a non-commercial Internet sound repository called The Freesound'. The project was launched in 2005 as an initiative of the Music Technology Group, a part of the Audiovisual Institute (Department of Information and Communication Technology) of Pompeu Fabra University in Barcelona. MTG is an interdisciplinary group which conducts research concerning sound processes; it also studies descriptions of the content of musical compositions, interactive sound systems, music and sound perception, and technologies connected to music social networks.

The sounds are shared in accordance with Creative Commons licenses, and as a result they can be used freely and by anyone. On The Freesound, one can search for sounds using keywords, upload and download sounds and communicate with representatives of the sound art community. Field recordings uploaded to the repository have to be tagged, geotagged (with a clear indication of the place of origin) and described in detail (what this sound is, its context, date and time of recording, etc.). In 2017, more than four million users were registered on the website. The most active user has uploaded almost 38 ,ooo sounds and the website as a whole contains more than $38 \mathrm{I}, 000$ sounds 6 .

In 2009, there were not so many field sounds. This is why I was able to listen to most of them. Though they were localized and described, they seemed to me out of context. I was curious why the people recording them chose and decided to share those particular sounds and not others. At the same time, I was interested who the people recording them were; so I did some research in the area of digital ethnography. I chose almost 50 field recordings - ambiences registered on each continent, in different cultural contexts. The choice was not arbitrary, but it was definitely far from the methodologies used in the social sciences. For me, the key issue was the technical aspects: I chose the recordings with the highest quality (shared in the form of uncompressed audio files), whose duration was long enough to feel the character of a given place.

5 https://freesound.org/ (accessed on 02.08.2018).

6 https://freesound.org/ (accessed on 02.08.2018), https://blog.freesound.org/ (accessed on 02.08.2018), https://en.wikipedia.org/wiki/Freesound (accessed on 02.08.2018), https://www.alexa.com/siteinfo/freesound.org (accessed on 02.08.2018). 
Then I contacted their authors asking for additional information. I talked to some of them by email or Skype. This is how I learnt where they came from, how mobile they were, what they did for a living, why they were in the places whose sounds they registered, why they did those recordings and why they decided to share them.

“(...) Recording sounds is very exciting, finding the right place at the best moment. It's like taking art pictures (...) I have always a recorder in my bag. I record like others take photographs. For my job and for pleasure too." [Arnaud/arnaud coutancier $]^{7}$

"I love recording sounds. I do it everywhere (...) I'm slowly building a sound archive. Generally, I wouldn't say recording is anything more than collecting sounds for music. I always have Edirol on me, regardless of where I'm going, why and what for. I'm particularly sensitive and responsive to sounds. Generally, I'm interested in those sounds which I know will disappear." [Baruch/gottlieb]

“(...) I travel owing to music and sound projects, and while travelling I either collect sounds or use them later in music. I like collecting sounds, because they express much more than a photograph or a video. When I'm in a city, I like rambling around, just to find some unexpected sounds." [C-drík/cdrk]

Most of the field recordings which led me to meeting their authors were stereotypical: in the countryside, they were natural sounds and in the cities, the sounds of traffic flow (opposition countryside/city $=$ silence/noise $=$ hi-fi/lo-fi). Thus, they reflected some stereotypical audio impressions: in tropical forests, recording cicadas or exotic birds is a must; as are muezzin calls in the Middle East; the French language in France; religious elements of the soundscape in Central and Eastern Europe; street fairs, bicycles and traffic chaos (specific traffic sounds dominated by cars honking) in South-East Asia; water in the Pacific Islands, and in the world outside Europe - music folklore (traditional singing and the sound of musical instruments). Generally speaking, regardless of the location, the sounds deemed worth recording are usually either exotic ones or typical sounds reflecting the character and atmosphere of a given place. What is often collected are ambiences from the most popular tourist sites or traditional events related to some yearly customs.

Intense cicada - Quesada Gigas - ambience from Catamarca ${ }^{8}$

7 In the text every effort has been made to retain the punctuation, spelling and grammar of the original sources, i.e. e-mails from my research partners. Some minor alterations have been made in cases where errors made the quotations difficult to read.

8 https://rcin.org.pl/Content/I220I5/Audio/WA308 I522II P366 Collecting-Sounds ooooI.wav. 
Most importantly, these are recordings made by representatives of European-American culture, mostly (white) middle-class males, characterized by (tourist and professional) mobility. Therefore, field recordings often contain sounds heard from the tourist's perspective, which makes them somewhat akin to sound postcards or souvenirs (see Bijsterveld and van Dijck 2009). More often than not, they are actually a kind of additional outcome of professional work and are usually made by traditional musicians, DJs, electronic music producers, sound directors, reporters, IT specialists, artists, scientists and film makers. They might also be gathered for various sound art or scientific projects, usually interdisciplinary in nature, whose aim is to document and maintain the sound tapestry of cities and the environment. Such projects almost always have an Internet version, usually in the form of sound maps. Sometimes, these field recording projects or private collections are connected with other Internet spaces, such as YouTube or Vimeo videos, Soundcloud compositions, blogs, other websites, etc.

Field recording understood as a cultural practice has a multifaceted nature: it can be perceived from different perspectives and interpreted in many different ways. Firstly, such a practice can be looked upon from the point of view of postcolonial studies and interpreted as rooted in the colonial trend of collecting elements of non-western and exotic folklore. From outset, field recording was aimed at creating collections. As was the case with the $17^{\text {th }}$ century trend for collecting material things, the trend of collecting sounds is also politically-marked and ideologically-grounded (Edmondson 2016, 30-32). This is why field recording is a product of activities that are socially-conditioned as well as of subjective experiences. It is thus necessary to analyze this interest in objects in a wider socio-historical context, as exotically-sounding records brought from Asia, Africa, Australasia or South America can be equated with trophies and souvenirs.

9 https://rcin.org.pl/Content/I220I5/Audio/WA308 I522II P366 Collecting-Sounds 00002.wav. Io https://rcin.org.pl/Content/I220I5/Audio/WA308 I522II P366 Collecting-Sounds 00003.wav. 

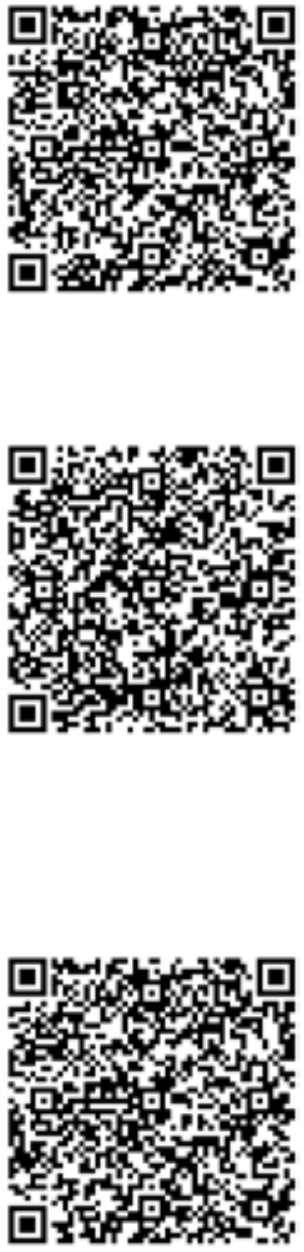

"This was on this huge market Kikar Shabat in Jerusalem. I was on holiday in Israel during a Jewish Festival called Sukkot. I live in England and I'm a Jew. I was in the market to buy lulav and estrog. It was a huge traditional festive fair opened a week after Sukkot. It was my first trip to Israel since I was a teenager. There was bustle, a lot of Jews. I recorded this sound, because I wanted to have a souvenir, to keep this experience of this bustle and hubbub". [Mike/Sparrer ${ }^{\text {II }}$

"I am a journalist myself, working for a public radio and television in the Netherlands. As a radio reporter I visited Bangladesh just after the cyclone Sidr hit the coastal area in November 1997 (...) I travelled to the islands on a boat. On that boat were two boatmen and one of them started singing while we were sailing. As I geotagged this song you can see exactly where it was. I was staying at that time in Pirojpur, took a taxi to the river and got a boat. A long tall typical motorboat. It was a journey of three-quarters of an hour during which he sang two songs." [Jeroen/zeshoog] ${ }^{12}$

"I was on vacation in Mala, living in a self-catering holiday cottage, together with my girlfriend (we're together for in years now), recovering from a heavy workload in the second half of 2008. We were sitting outside, probably sipping a beer, when we heard the sound of bells approaching. Stepping on the stones that enclose the little forecourt of the cottage, we could just see the goat herd being driven by. I dashed for my Rog (recording equipment) to get that impression - but too slowly too late, it seemed, the herd had disappeared and with it the sound. When I was about to pack my Ro9 again the sound appeared to come back, so I dashed down the driveway, just in time to see the herd pass, and then I followed it a couple of hundred meters, walking behind the herd, trying not to breathe or make stepping sounds, eventually, when dogs started barking and a car approached from behind, I stopped and let the goats go on, the car passes, honks ... and I cut the recording and walk back to the cottage." $[\text { Peter/ptroxler }]^{13}$

Field recording is also a cultural practice, which contributes to a democratization of the senses and to appreciating the sound image of certain places. It substitutes or complements the visual experience of the world (See: Stoller 1989; Classen 1993; Seremetakis 1994; Synnott, Classen and Howes 1994). As a form borrowed from 
cultural phenomena and most of all, as a tool of preserving and documenting them, it has been practiced since the end of the $19^{\text {th }}$ century, first in social studies, which themselves developed more or less simultaneously with the invention of the phonograph - a technology allowing for sound registration (Caughie 20I0, 9I-92). This invention brought about new listening practices and firmly established a special modernistic involvement in sound. Field recording at the turn of the $20^{\text {th }}$ century was technologically limited (recorders were large, carriers were ineffective and the recording quality was low) and was characterized by very defined substantive restrictions (Brady 1999). Moreover, it had nothing to do with soundscape registration. At the time, field recording was mainly used for documenting folklore, so the recordings contained mainly vocals and music.

One of the examples of early field recording, in this case from American anthropology, is the sound documentation of Native American folklore compiled by Franz Boas, whose first sound records were created at the turn of the $20^{\text {th }}$ century. A sound recording collection gathered in the Robert Lowie Anthropology Museum in Berkeley is also worth mentioning. The oldest samples there were registered on wax-coated cardboard cylinders in 1900 (Keeling 199I). Collecting field records of folklore in the USA gained popularity in the I930s, when the Works Progress Administration was established, which supervised and supported the Federal Writers Project. A folklore section was one of the parts of this project. Its task was to conduct field research on folklore, an important aspect of which was to focus on registering the sounds of traditional songs, music and stories.

The reason why I mention the collecting nature of the beginnings of field recording is that it reflects a long-standing understanding of sound in anthropology. Until the end of the 1980s, when the theoretical and methodological foundations of the democratization of the senses were developed, only sounds that were connected to music or, in a wider sense, to folklore were deemed worth registering, documenting and distributing. Only then did the anthropology of sound, standing in a way in opposition to the anthropology of music, resign from artificially separating musical and non-musical (environmental, mechanical and non-vocal) sounds (Feld 1990). As a result, it connected acoustic manifestations of social life with their cultural, historically conditioned meanings and became interested in the social dimension of sound creation its sources, causal dynamics and reception - searching for answers to the questions of who has the right to produce and manifest certain sounds, what is audible and who is predestined to listen. It is in this context that the modern form of field recording appeared.

Field recording is a practice which can also be analyzed in the context of collective or individual, subjective memory. Usually it has some emotional background and is connected with sentimental feelings: with nostalgia and a longing for the old days, for long-gone landscapes or for past activities and situations. 

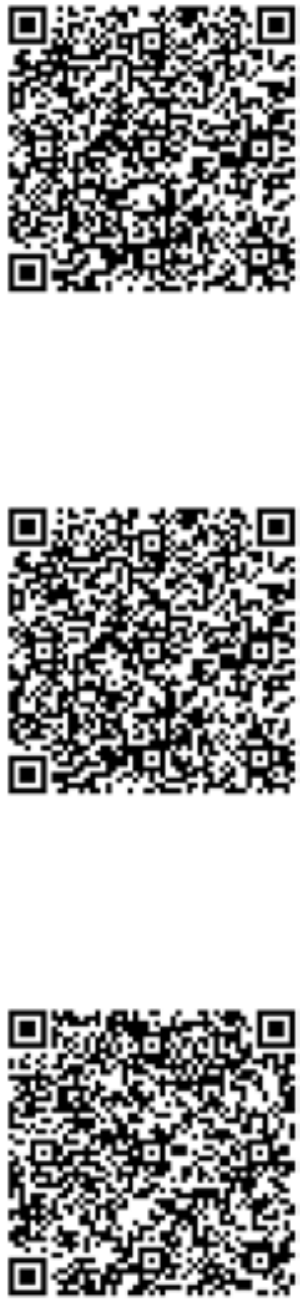

much satisfaction to be able to have as much or more stamina for this activity than they havel When we are on these trips, we hike up peaks, catch fish, drink some whiskey around campfires and enjoy our time in the beautiful solitude. My memories of this trip were of the steep, hot hike from the desert to the cool meadow; the overall beauty of the nature, the absolute solitude of our campsite near the meadow; the strenuous hike to the top of Olancha Peak; the camaraderie of my friends; and, of course the sound of the frogs in the meadow. The frog sounds were

"The place where I did record the sound "saunan lämmitys" is our family's summerhouse. My father bought it year 1955 . He was born nearby in Virojoki village in I9II and passed away in 2003. As you know Sauna a is very relaxing and important thing to Finns. We like the warm and silence of sauna atmosphere and heating the sauna is almost religious to us. For me it is remembering moments I spent with my dead father and other relatives. I am 56 years old internist and living $600 \mathrm{~km}$ away from that place but still I visit there for about 2 months yearly." [Timo/timofei $]^{\text {I4 }}$

"I was the class teacher at that time. It was a class trip, usually organized near the end of the schoolterm in summer. The pupils went there by bike to have a barbecue at the sandy banks of the river Rhine near Dusseldorf. The landscape around is mostly dominated by agriculture and glasshouse cultures. You find a mixture of former villages nowadays completely suburbanized. The population finds jobs in the nearby urban centers like Dusseldorf, Neuss and other big cities. The reason why I recorded the scene is simply because I am interested in collecting sounds in general by doing recordings in different surroundings like nature, cities and everything between. My memories about the event are that it was a relaxing and funny atmosphere, which is not always the case while teaching in a classroom" [Reinhard/reinsamba $]^{15}$

"The sound comes from a meadow in the Sierra Nevada Mountains in California. The meadow is at an elevation of 2400 meters near a mountain named Olancha Peak, which is 3700 meters in altitude. I have a group of friends with which I backpack (trek) into the mountains. Our goal was to spend some time in the mountains and hike to the top of Olancha Peak (...) By the time we reached the meadow, we were in a forest and there was still snow on the ground in some places. We took the trip in June of 2006. The Sierra Nevada Mountains are a large mountain range. Much of the range is protected by national parks or preserved areas we call 'wilderness areas' (...) I have been backpacking for nearly 40 years and I will hopefully continue with this challenging activity for 40 years more! Many of my friends are much younger than I am and it gives me 
astounding to me and I would listen in awe of the creature's instinctual desire to reproduce and continue the existence of their kind. Surely there were different species in the meadow for some of the frog sounds were different than others. The sounds only occurred after the Sun went down for the evening. I stood next to the creek in the meadow and recorded the sounds using my digital camera." [Peter/plentzIg6o] ${ }^{16}$

Finally, field recording is a cultural practice which tells a lot about knowledge distribution modules (field recordings are after all a type of field knowledge) - about how knowledge is distributed and shared, opening endless possibilities of verification, use and also manipulation. Such a community as the one belonging to The Freesound is a great example of such a cultural practice. Field recordings in the project have free licenses, which allow for their unlimited use. In this way, for example, the Polish countryside ambience may become a part of a soundtrack for a computer game, a theatre play, a background of a university lecture, it may be mixed into a musical piece, etc.

"It was recorded on Sunday, morning of the $28^{\text {th }}$ of September as some of the slower runners of the Berlin Marathon made it past Torstrasse near my flat. I was out to buy some bread for breakfast, but I usually bring a camera and my Edirol R-I recorder whenever I go out. Since I was freshly returned to Berlin I guess I was sensitive to the more antiquated sounds which still survive there, like that of the organ grinder. I am generally interested in how human beings are replacing the presence of Nature with an artificial environment made entirely by human hands (and thus far more understandable, it is hoped). In this new Human Nature, the sounds of Nature are also Human made. I write about these things, but I also use the sounds in my videos and my interactive and generative media work, so generally I am wandering around building up my archive of media documents for use as material in future works." [Baruch/ gottlieb $]^{17}$

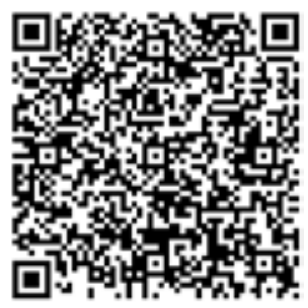

"I'm something of an untrained, unofficial cultural anthropologist myself. I have a business interviewing people to capture their personal histories. I'm always interested how people fit into their world and how they affect their world. I'm a graphic designer who works in the same building as the printing presses that I recorded. I walk past the presses every day on my way to talk to the folks in the prepress department. I'm on friendly but not drinking terms with the pressmen. I'm a friend with the prepress manager. Three Heidelberg presses are installed side by side in an open warehouse-like room. The presses are about twenty feet long and about five feet high. With their series of four humps or mounds where each printing cylinder is located, the presses remind one of giant, gray, mechanical caterpillars. Each press has a cyan cylinder, https://rcin.org.pl/Content/I220I5/Audio/WA308 I522II P366 Collecting-Sounds oooro.mp3. 

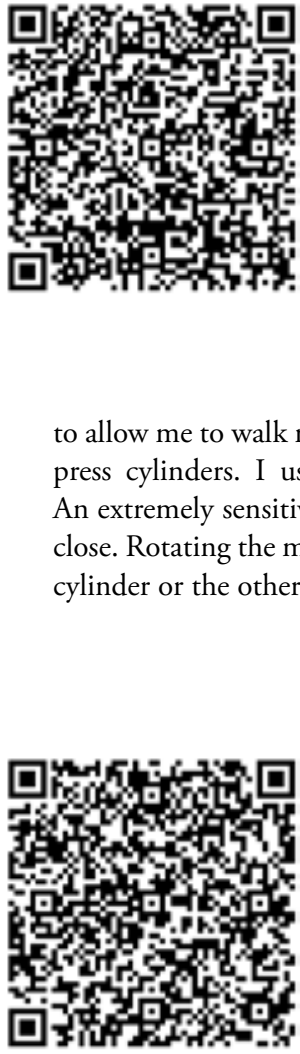
clear that he passionately believes what he is saying. He was unaware that I was recording him. I wish I had captured his whole sermon. He, and other members of his church visit the centre of York quite often, and preach there. I don't know the name of his church." [Jools/vedas] ${ }^{\text {tg }}$

Field recording as an act of actively listening to surroundings in an open, exploratory way changes how we think about sound, music productions and the world as a whole. But what are we specifically talking about when we say "field recording"? The earliest examples of this practice were colonial powers documenting their subjects to aid Western people understand the world. Access to recordings of non-Western music in particular had a profound influence on music in the $20^{\text {th }}$ century; but this 
is a story intimately associated with exploitation since many key early recordings are connected to state institutions or private foundations.

Today, field recording has expanded into other contexts and when we use this notion, we can be referring to any number of things: measuring how human sounds affect the ecology of natural ecosystems; studying acoustic tourism, which is being recognized even as a separate industry; or considering how field recording is distributed and who is listening to it. It is important to take into account that the field is now virtual and its sounds inevitably tend to recur somewhere online. Sound engineer, Mark Smith, claims that the effects of field recordings might not even be audible and, in this sense, field recording is a way to manipulate how people feel about sounds in potentially profound ways (Smith 2016).

Field recording opens many perspectives because it is located at the intersection of several powerful forces, such as human perception, history, science and technology. The possibility of unlimited archiving and distribution of recorded sounds can be regarded as sonic journalism, based on the idea that all sounds, including non-speech, give information about places and events in a specific cultural context and that listening provides valuable insights, different from, but complimentary to, visual images and language. This does not exclude speech, but redresses the balance towards the relevance of other sounds. In practice, field recordings become the means to achieve this. They can, of course, be used in many ways. Sonic journalism occurs when field recordings are allowed appropriate space and time to be heard in their own right, when the focus is on their original factual and emotional content, and when they are valued for what they are rather than as source material for further work, as often is the case in sound art or music. The interpretation of sound benefits from the knowledge of context in the same way that captions and titles enhance photographs. However, field recordings convey far more than just basic facts. Spectacular or not, they also transmit a powerful sense of spatiality, atmosphere and timing, and this applies even when the technical quality is poor. These factors are key to our perception of place and movement, and so add substantially to our understanding of events and issues. They give a compelling impression of what it might actually be like to be there.

\section{BIBLIOGRAPHY}

B all a r d T. 2018. Listening to the 'music of the future' in the future, http://www.documentjournal.com/2018/03/listening-to-irv-teibels-environments-in-the-future/ (accessed 0I.05.2018).

B i j st e rveld K. and van D i j ck J. (eds.). 2009. Sound Souvenirs Audio Technologies, Memory and Cultural Practices. Amsterdam: Amsterdam University Press.

B r a d y E. 1999. A Spiral Way: How the Phonograph Changed Ethnography. Jackson: University Press of Mississippi. 
Ca ugh i e P. L. 20I0. Audible Identities: Passing and Sound Technologies. Humanities Research I6, 9I-IO9.

Cho e S. H. and Ko Y. M. 20I5. Collective Archiving of Soundscapes in Socio-Cultural Context. iConference, https://www.ideals.illinois.edu/handle/2142/73464 (accessed 02.08.2018).

$\mathrm{Cl}$ as se n C. 1993. Worlds of Sense: Exploring the Senses in History and Across Cultures. New York: Routledge.

$\mathrm{Cu}$ s a ck P. 20I2. Field Recording as Sonic Journalism, http://sounds-from-dangerous-places.org/sonic-journalism (accessed 02.08.2018).

E d m o n d s on R. 20I6. Audiovisual Philosophy and Principles. Paris: UNESCO.

Feld S. 1990. Sound and Sentiment: Birds, Weeping, Poetics, and Song in Kaluli Expression. Philadelphia: University of Pennsylvania Press.

F i t z g e r a ld B. (ed.). 2007. Open Content Licensing: Cultivating the Creative Commons. Sydney: Sydney University Press.

$\mathrm{K}$ a n g J. 2006. Urban sound environment. London: CRC Press.

Ke e l in g R. 1991. A Guide to Early Field Recordings (1900-1949) at the Lowie Museum of Anthropology. Berkeley: University of California Press.

Le s s i g L. 2004. Free culture. How Big Media Uses Technology and the Law to Lock Down Culture and Control Creativity, http://www.free-culture.cc/index.html (accessed I0.07.2017).

L i n W. 20I5. The hearing, the mapping, and the Web: Investigating emerging online sound mapping practices. Landscape and Urban Planning 142, 187-197.

M o o r e T. 1992. Care of the Soul. New York: Harper Perennial.

O'R e illy T. 2005. What Is Web 2.0? Design Patterns and Business Models for the Next Generation of Software, http://www.oreillynet.com/pub/a/oreilly/tim/news/2005/og/30/what-is-web-20.html (accessed 02.08.2018).

Pija nowski B. C. et al. 20Ir. What is soundscape ecology? An introduction and overview of an emerging new science. Landscape Ecology 26(9), I213-I232.

Porterfield N. 1996. Last Cavalier: The Life and Times of John A. Lomax, I867-1948. Urbana and Chicago: University of Illinois Press.

Ra i mbault M. and D ubo is D. 2005. Urban Soundscapes: Experiences and Knowledge. Cities 22(5), 339-350.

S c h a f e r R. M. 1977. The Soundscape: Our Sonic Environment and the Tuning of the World. Rochester: Destiny Books.

S e r e m e t a k is N. (ed.). 1994. The Senses Still: Memory and Perception as Material Culture in Modernity. Chicago: University of Chicago Press.

$\mathrm{S} \mathrm{m}$ i th M. 20I6. Field recording: The practice and its possibilities, https://www.residentadvisor.net/features/2709 (accessed 02.08.2018).

S t a n is z A. 20I2a. Akustemologia wspótczesności. Refleksja nad potencjatem antropologii dźwięków, http://www.cyfrowaetnografia.pl/dlibra/doccontent?id=4734 (accessed 02.08.2018).

$\mathrm{Stanisz}$ A. 20Izb. Audiografia i dewizualizacja antropologii w badaniu miejskiej audiosfery. In R. Losiak and R. Tańczuk (eds.), Audiosfera miasta. Prace Kulturoznawcze XIII. Wrocław: Wydawnictwo Uniwersytetu Wrocławskiego, 99-III.

$\mathrm{S}$ t a n i s z A. 20I4. Audio-antropologia: praktykowanie dyscypliny poprzez dźwięk. Prace Etnograficzne $42(4), 305-318$.

St a n is z A. 20I7. Field recording jako metoda etnografii poprzez dźwięk. Przegląd Kulturoznawczy 3I(I), I-I9.

S t e r n e J. 2003. The Audible Past: Cultural Origins of Sound Reproduction. Durham: Duke University Press. 
S t o 11 e r P. 1989. The Taste of Ethnographic Things. The Senses in Anthropology. Philadelphia: University of Pennsylvania Press.

Synn ot t A., Classen C. and Howes D. 1994. Aroma: The Cultural History of Smell. London and New York: Routledge.

Truax B. 1996. Soundscape, Acoustic Communication \& Environmental Sound Composition. Contemporary Music Review I5(I), 49-65.

Tru a u x B. 2008. Soundscape Composition as Global Music: Electroacoustic Music as Soundscape. Organised Sound $\mathrm{I} 3(2)$, $103-\mathrm{IO} 9$.

Tr u a u x B. 2012. Sound, Listening and Place: The Aesthetic Dilemma. Organised Sound I7(3), I-9.

Uimonen H. and Ky tö M. 2008. Soundscape and Emplaced Pasts - Analyzing One Hundred Finnish Soundscapes. In S. Bernat (ed.) Dźwięk w Krajobrazie jako Przedmiot Badań Interdyscyplinarnych. Prace Komisji Krajobrazu Kulturowego II. Lublin: PTG, I5-2I.

We s t e r k a m p H. 1974. Soundwalking. Sound Heritage 3(4), I8-27.

We st e r k a m p H. 2000. Exploring Balance \& Focus in Acoustic Ecology. Soundscape II(I), 7-I3.

Wy n e s J.A. 2008. Soundscape as discursive practice, http://soundartarchive.net/articles/Wyness-2008.pdf (accessed or.04.20II).

Yung B. and Rees B. (eds.). 1999. Understanding Charles Seeger, Pioneer in American Musicology. Urbana and Chicago: University of Illinois Press.

\section{List of sounds:}

Sound I: rfhache. 2008. Intense cicada - Quesada Gigas - ambience from Catamarca https://freesound.org/people/rfhache/sounds/64I22/ (accessed I2.05.2020), page I32. This work is licensed under the Attribution License.

Sound 2: grololo. 2007. A street in downtown Delhi

https://freesound.org/people/grololo/sounds/34864/ (accessed I2.05.2020), page I33.

This work is licensed under the Creative Commons o License.

Sound 3: snog. 2009. Water lap from South East Misool Island off West Papua

https://freesound.org/people/snog/sounds/6703I/ (accessed I2.05.2020), page I33.

This work is licensed under the Attribution Noncommercial License.

Sound 4: Sparrer. 2008. Lulavmarket

https://freesound.org/people/Sparrer/sounds/51389/ (accessed I2.05.2020), page I24.

This work is licensed under the Attribution License.

Sound 5: zeshoog. 2008. Pani Water Song Bangla

https://freesound.org/people/zeshoog/sounds/59816/ (accessed I2.05.2020), page I34.

This work is licensed under the Creative Commons o License.

Sound 6: ptroxler. 2009. Goats on Lanzarote

https://freesound.org/people/ptroxler/sounds/65753/ (accessed I2.05.2020), page I34.

This work is licensed under the Attribution License.

Sound 7: timofei .2008. Saunan lämmitys

https://freesound.org/people/timofei/sounds/60745/ (accessed I2.05.2020), page I36.

This work is licensed under the Attribution License.

Sound 8: reinsamba. 2008. School excursion,

https://freesound.org/people/reinsamba/sounds/55242/ (accessed 12.05.2020), page 136.

This work is licensed under the Attribution License. 
Sound 9: plentzi960. 2008. Frogs

https://freesound.org/people/plentzig6o/sounds/59487/ (accessed 12.05.2020), page 136.

This work is licensed under the Sampling+ License.

Sound I0: gottlieb. 2008. Organ grinder

https://freesound.org/people/gottlieb/sounds/61789/ (accessed I2.05.2020), page I37.

This work is licensed under the Attribution License.

Sound II: KMerrell. 2008. Printing Press

https://freesound.org/people/KMerrell/sounds/64702/ (accessed I2.05.2020), page I38.

This work is licensed under the Sampling+ License.

Sound I2: vedas. 2008. Street preacher

https://freesound.org/people/vedas/sounds/62840/ (accessed I2.05.2020), page I38.

This work is licensed under the Attribution License.

\section{Author's contact:}

Dra. hab. Agata Stanisz, prof. UAM

Department of Anthropology and Ethnology

Adam Mickiewicz Univeristy, Poznań, Poland

E-mail: stanisz@amu.edu.pl

ORCID: oooo-oooI-9649-I489

\section{(c) $(1) \Theta$

